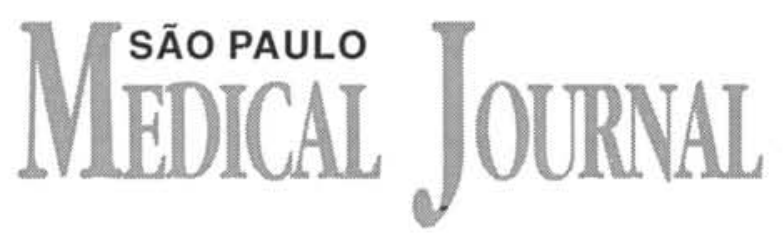

Presentation

Linamara Rizzo Battistella

\title{
Editor and authors: common way
}

Demand of perfection in publications is not an isolated task of the Editor and the Editorial Board. This objective is shared with the people interviewed who dedicate a great part of their time in the channeling task of adequate scientific work to the publishing rules established by the Magazine and provide for the necessary justifications to the reporters.

Before reaching this phase, the author must solve a very important question: select the most indicated journal for his work. Before solving this question, he must be aware of who are his possible readers and how large is the interest for this subject.

Editor must also respect characteristics of each article submitted and verify, based on well defined criteria, if the work fits the profile of the magazine and if interesting to their readers.

In order each one accomplishes his task correctly, it is necessary to be aware of the responsibility of such journal counting with the uphold of Index Medicus and Medline System.
Cataloguing system was a great advance for the interchange of information extremely important for the scientific updating and development. Informatization through the Medline System helped the access to literature available and transformed bibliographic search in an agreeable and reasonable task.

When submitting some article to an indexed magazine, the author should exactly know what are the critical elements this publication follows. National Library of Medicine, in July, 91, presented following criteria among others:

"Goal-Public: Index Medicus and Medline systems are destined, particularly, to professionals of the health area, such as: technicians, educators, administrators and students. Professionals of the health area are considered: physicians, nurses, dentists, veterinarians and other kind of professionals related to the health involved with the searching and attendance. 
Inhold characteristics: Journals considered for indexing should bear one or more of the following information:

a) Original searching abstract;

b) Original clinical observations with the corresponding analysis and discussions;

c) Analysis of the philosophic, ethic or social aspects of the health and biomedical sciences;

d) Critical revision;

e) Statistics;

f) Description or assessment of methods and procedures;

g) Description of cases or clinical meetings, with the corresponding discussions.

Geographic extent: High quality and the most useful journals are selected, independently from the place of the issue. With the purpose of enabling a worldwide extent, special attention is given to search, social health, epidemiology, types of health attendance and local diseases. Publications covering subjects already well represented in the Index Medicus or Medline or those that are published for a locally interested people only, are usually not selected.

Understanding of these criteria will be directly influenced by the purpose of the issue. Four classes of publications are known:

1. Search magazines: Preferably dedicated to: reports on original investigations in the areas of biomedical and health sciences, including search in the basic sciences; clinical essays by therapeutic agents; technical activities and therapeutic and diagnostic methods; epidemic, behavior and educational studies, interesting to the health area.

2. Clinical magazines: Their main purpose is the registering of the present situation of the health practice, enabling useful information for the ininterrupted training or teaching of technicians. This is performed by publishing reports of different cases, discussions and introduction to new techniques, assessments of actual practices and comments.

3. Revision magazines: Show current knowledge and practices, comprising most recent improvements of principles and practices accepted or, condensing and examining usual points of view in comparison to controversies in knowledge and practices. Revision magazines provide basic information for technicians, searchers, students, residents and others who look for a general view or the present condition of a certain area.

4. General magazines: Inhold elements such as the above described and, frequently, bringing social, politics or economical comments and analysis. Are usually destined to a wide-ranging public, not limited to only one specialty."

Editors of the Revista Científica know current difficulties for introducing a new publication in the Index Medicus.

Ann Colaianni, Associate Director, Library Operation - National Library of Medicine, in a recent symposium sponsored by Bireme and PAHO (Pan America Health Office) emphasized the idea of a Regional bibliographic database such as "Artemise in Mexico and LILAC for Latin America" as an alternative or complementary solution due to difficulty new journals face trying to be registered in the Index Medicus.At this same opportunity, showed that, from the total of articles published in 1983, 1.7\% were in Spanish and Portuguese languages, decreasing to $1.4 \%$ in 1984 . In the same period, articles in English reached $74 \%$ in 83 and $86 \%$ in 93, proving that English is considered as being a scientific language.

SPMJ is the oldest magazine included in the Index Medicus and tries to follow tendencies to continue being up-dated.

To attend communication needs between the home authors and the American and Scientific communities, São Paulo Medical Journal has been edited since 1992 and continues being printed in English, comprising a worldwide distribution.

From 1995 on, we came back to a bimonthly publication to attend requirements and with special emphasis to Clinical Implications of Basic Research. The most important is that through these reformulating, São Paulo Medical Journal intends to reach the twenty six thousand associates of the APM, carrying out its compromise in informing and updating medical community of this country and guarantee a communication channel between Brazilian authors and the foreign public.

When submitting his work to RPM/SPMJ, the author is contacting the end-public of Index Medicus and Medline system. In 1994, we have introduced the SPMJ into the Institute for Scientific Information and, this way, we will reach the Current Contents public. This communication 
must be properly valued, scientific frontiers must be more and more approached and communication should be the key-word now we are entering the third millennium.

So is defined responsibility of the Relaters, Editorial Council and Editor in Chief, as they are responsible for the scientific image diffusion of the magazine and, therefore, of the country in front of the international community.
São Paulo Medical Journal is one more facility offered by the Associação Paulista de Medicina, offered at no cost to all associates, having in mind the union of the Universities and Medical Institutions in the whole country. A common way Authors and Editors go through together. 